\title{
Assessment of Posture and Musculoskeletal Pain in School Going Girls Using Backpacks
}

\author{
Snehal Dharmayat ${ }_{\text {MPT, }}^{1}$ Sangita Shrestha ${ }^{2}{ }_{\text {MPT })}$

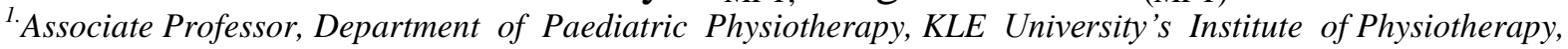 \\ Belgaum, India, \\ 2.(MPT), Department of Paediatric Physiotherapy, KLE University's Institute of Physiotherapy, Belgaum,
} India,

\begin{abstract}
Purpose: Musculoskeletal symptoms in school going children are growing numerously in present context and are multifactorial in origin and heavy backpacks being one of them. Along with pain, posture is another important aspect which needs to be addressed as children are developing incorrect posture as a result of heavy backpacks.

Methods: This was a cross- sectional study done on 500 school going girls aged 10-14 years from the private and government schools of Belgaum city which included assessment of posture and musculoskeletal pain. The site of pain was assessed by using Body Diagram Chart, intensity of pain was assessed by Visual Analogue Scale (VAS) and posture was assessed by New York Posture Rating Scale (NYPR).

Results: The most painful site was found to be shoulder followed by leg, hip, neck, and thorax. $46 \%$ of school going girls had shoulder pain out of which 33\% had both shoulder pain $7.8 \%$ had right side pain and $5.2 \%$ had left side pain $(p<.001)$. This study also showed that $34.7 \%$ of 14 years age girls had forward head posture.Forward head was seen increasing with increase in age $(p<.001)$

Conclusion: Pain and postural abnormalities are associated with the use of backpacks in children. Commonest site of pain is shoulder and frequent postural abnormality noted was a forward head posture.
\end{abstract}

Keywords: Posture, Musculoskeletal pain, Backpacks

\section{Introduction}

Worldwide more than $90 \%$ of school children carry backpacks for transporting their belongings to and from school. ${ }^{1,2}$ Repeated carrying of heavy loads such as backpacks can be one of the causes for musculoskeletal symptoms in school going children, where there is additional stress on rapidly growing adolescent spinal structures. ${ }^{3,4}$ The American Occupational Therapy Association, the American Academy of Orthopaedic Surgeons and The International Chiropractic Paediatric Association suggest that backpack load should not be more than 10\%. The American Physical Therapy Association suggest $15 \% .{ }^{5}$ Forward lean of trunk could be a result of carrying backpacks along with pain and disability in school going children. The various problems which might arise because of the use of heavy backpacks could be deformation in the natural curve in the back, muscle strain, irritation to the rib cage, chronic back and neck pain, shoulder strain, general exhaustion, ankle injuries, pain in the wrist, elbow and knee. ${ }^{6}$

Efficient erect adult human posture is believed to reflect the least amount of physical activity required to maintain body position in space $7,8,9,10,11$, and which minimises anti-gravity stresses on body tissues. This is considered to occur in the unloaded state when the body is closely aligned with a vertical reference (reflecting gravity). Application of external forces to the body (such as in a backpack) is commonly associated with postural deviation from close alignment with the gravitational axis. Unloaded posture that habitually deviates from gravitational alignment has been associated with spinal pain. ${ }^{12}$ While posterior loads will necessarily change body posture because of changes to centre of gravity, efficient adult posterior load carriage (that which minimises spinal tissue stress) has been related to minimum load, the position of the backpack close to the body's centre of gravity, and the capability of the backpack to accommodate the load close to the spine. ${ }^{13,14}$ While there is no evidence to suggest that these parameters should not also be applied to adolescents, the effect on their postural responses to load of musculoskeletal development, muscle strength, relative weight to load, gender and age have not been explored in the adolescent population. Thus there may be differences in adult and adolescent responses to posterior loads which may make adult 'rules of thumb' inappropriate for adolescents. One of the common postural deviations found is kyphosis which causes bowing of the back leading to hunch back or slouching posture. This is often seen in early adolescents, especially in girls who are growing rapidly and developing secondary sexual characteristics. ${ }^{15}$ Literature reports various studies on the effects of backpacks in 
school going children; however there are less number of reported studies on prevalence of musculoskeletal pain and deviation in postures exclusively in girls more in the Indian scenario, hence the present study was undertaken in an attempt to fill this lacuna.

\section{Materials And Methods}

An approval for the study was obtained from the Institutional Ethical Committee. 500 school going girls between the age group of 10-14 years. Children were taken from private and government schools after obtaining informed assent from parents before conducting the study. Subjects with history of recent musculoskeletal injuries or congenital deformities were excluded. Demographic information were taken which included subject's age, height and weight followed by the determination of site of pain by using Body Diagram Chart. ${ }^{16}$ The site mainly observed were neck, shoulder, arm, elbow, hand, hip, thigh, knee, leg, upper back, thorax and lower back. The subject had to put a tick mark on the chart denoting the area of pain in their body.

The assessment of posture was done by New York Posture Rating Scale in which subjects were asked to stand in position of comfort and look forward on the wall at their eye level in order to establish a level head position. ${ }^{17}$ Then the plumb line was kept slightly anterior to right malleolus for assessing posture in sagittal plane and at midpoint between the feet for assessing in the frontal plane. Scoring is done as 5, 3, 1 for no deviation, some deviation and marked deviation respectively for each 13 criteria in the rating scale of which components are head, shoulder, spine, hip, feet, arches in the frontal plane and head, chest, shoulder, upper back, trunk, abdomen and low back in the sagittal plane.Pain was assessed by a $10 \mathrm{~cm}$ Visual Analogue Scale. VAS is continuous scale comprising a horizontal or vertical line, usually 10 centimetres $(100 \mathrm{~mm})$ in length, anchored by 2 descriptors, one for each symptom in which no pain is score of 0 and pain as bad as it could be or worst imaginable pain is score of 100 . The respondent is asked to place line perpendicular to the VAS line at the point that represents their pain intensity. The score interpretation is: no pain $(0-4 \mathrm{~mm})$, mild pain $(5-44 \mathrm{~mm})$, moderate pain $(45-74 \mathrm{~mm})$, and severe pain $(75-100 \mathrm{~mm}){ }^{18}$

Table 1: Prevalence of shoulder pain among 10 to 14 years age group

\begin{tabular}{|l|l|l|l|l|l|}
\hline Age (Years) & No pain & Right side & Left side & Bilateral & Total \\
\hline 10 & $54(52.4 \%)$ & $3(2.9)$ & $5(4.9)$ & $41(39.8)$ & 103 \\
\hline 11 & $58(61.1)$ & $3(3.2)$ & $2(2.1)$ & $32(33.7)$ & 95 \\
\hline 12 & $70(67.3)$ & $1(1)$ & $3(2.9)$ & $30(28.8)$ & 104 \\
\hline 13 & $35(43.8)$ & $7(8.8)$ & $5(6.2)$ & $33(41.2)$ & 80 \\
\hline 14 & $53(44.9)$ & $25(31.2)$ & $11(9.3)$ & $29(24.6)$ & 118 \\
\hline Total & $270(54)$ & $39(7.8)$ & $26(5.2)$ & $165(33)$ & 500 \\
\hline
\end{tabular}

Table 2: Prevalence of shoulder pain according to BMI

\begin{tabular}{|l|l|l|l|l|l|}
\hline BMI & No pain & Right side & Left side & Bilateral & Total \\
\hline$<18.5$ & $207(54.2)$ & $29(7.6)$ & $14(3.7)$ & $132(34.6)$ & 382 \\
\hline$>18.5$ & $63(53.4)$ & $10(8.5)$ & $12(10.2)$ & $33(28)$ & 118 \\
\hline
\end{tabular}

For analysis two categories of BMI were merged i.e. (18.5 - 24.9) and (25-29.9) in which $34.6 \%$ of children having BMI less than 18.5 had bilateral shoulder pain.

Table 3: Prevalence of neck pain among 10-14 years age group

\begin{tabular}{|l|l|l|l|}
\hline Age & No pain & Pain & Total \\
\hline 10 & $93(90.3)$ & $10(9.2)$ & 103 \\
\hline 11 & $72(75.8)$ & $23(24.2)$ & 95 \\
\hline 12 & $96(92.3)$ & $8(7.7)$ & 104 \\
\hline 13 & $73(91.2)$ & $7(8.8)$ & 80 \\
\hline 14 & $110(93.2)$ & $8(6.8)$ & 118 \\
\hline Total & $444(88.8)$ & $56(11.2)$ & 500 \\
\hline
\end{tabular}

Table 4: Prevalence of forward head posture among 10 to 14 years age group

\begin{tabular}{|l|l|l|l|l|}
\hline Age & 1 (marked deviation) & 3 ( some deviation) & $5($ normal ) & Total \\
\hline 10 & $3(2.9)$ & $14(13.6)$ & $86(83.5)$ & 103 \\
\hline 11 & $1(1.1)$ & $25(26.3)$ & $69(72.6)$ & 95 \\
\hline 12 & $11(10.6)$ & $32(30.8)$ & $61(58.7)$ & 104 \\
\hline 13 & $7(9)$ & $31(39.7)$ & $42(51.30$ & 80 \\
\hline 14 & $13(11)$ & $41(34.7)$ & $64(54.2)$ & 118 \\
\hline
\end{tabular}


Table 5: VAS

\begin{tabular}{|l|l|l|l|l|l|l|}
\hline SITE & MEAN & SD & Q1 & MED & Q3 & RANGE \\
\hline Shoulder & 2.03 & 2.66 & 0 & 0 & 0 & $0-10$ \\
\hline Arm & .206 & 1.07 & 0 & 0 & 0 & $0-9.1$ \\
\hline Elbow & .24 & 1.12 & 0 & 0 & 0 & $0-8.2$ \\
\hline Hip & .28 & 1.37 & 0 & 0 & 0 & $0-8.9$ \\
\hline Thigh & .06 & .58 & 0 & 0 & 0 & $0-7.4$ \\
\hline Knee & .81 & 1.99 & 0 & 0 & 0 & $0-9.4$ \\
\hline Leg & .58 & 1.72 & 0 & 0 & 0 & $0-10$ \\
\hline Upper back & .21 & .99 & 0 & 0 & 0 & $0-9.1$ \\
\hline Thorax & .65 & 1.87 & 0 & 0 & 0 & $0-8.9$ \\
\hline Lumbar & .59 & 1.78 & 0 & 0 & 0 & $0-9.5$ \\
\hline Neck & .54 & 1.69 & 0 & 0 & 0 & $0-8.7$ \\
\hline
\end{tabular}

Mean and Standard Deviation of VAS score

\section{Result}

Single time measurement and data collected was analysed using Fisher Exact Test. The most painful site was found to be shoulder followed by leg, hip, neck, and thorax. $46 \%$ of school going girls had shoulder pain out of which $33 \%$ had both shoulder pain $7.8 \%$ had right side pain and $5.2 \%$ had left side pain $(\mathrm{p}<.001)$. (Table 1) Among these, girls of 10 years age group had the highest incidence of the bilateral shoulder pain with $39.8 \%$ whereas girls of 14 years age group had more right side shoulder pain followed by left side. $19.4 \%$ of girls of 14 years age group had knee pain in which $5.1 \%$ had right side and overall $11.8 \%$ had both sides pain. Similarly, $14.8 \%$ had pain in thoracic region which was highest in the 14 years age group had the most significant finding with $20.3 \%$ having pain $(p<.092) .13 .2 \%$ had lumbar region pain in which $15.3 \%$ were of 14 years age group. $12.8 \%$ had leg pain in which $12.6 \%$ of 10 years age group had bilateral pain. And $11.2 \%$ had neck pain where $24.2 \%$ was from 11 years group $(\mathrm{p}<.001) .4 .8 \%$ had hip pain out of which $3 \%$ had right side pain $1 \%$ had left side pain and $0.8 \%$ had bilateral pain. (Table 3)This study also showed that $34.7 \%$ of 14 years age girls had forward head posture. (Table 4) Forward head was seen increasing with increase in age $(p<.001)$. $33.3 \%$ of 13 years age group had upper back kyphosis. $18.6 \%$ of 14 years age girls had forward shoulder which was also increasing by increase in age $(\mathrm{p}<.025) .24 .3 \%$ of 10 years age girls had increased lumbar lordosis which was decreasing with age $(\mathrm{p}<.001)$.

\section{Discussion}

The present observational study was aimed to assess pain and musculoskeletal pain in school going girls who carry backpacks to their school. The present study showed significant difference in shoulder pain, leg pain, hip pain, neck pain and thoracic region pain. The subjects included in this study were school children between the age group of 10- 14 years. A cross sectional study conducted on primary school children between the age group of 6 to 12 revealed that $66 \%$ male and $65.7 \%$ female had musculoskeletal pain mainly back and neck. ${ }^{19}$ Similarly, a cross sectional study carried out to investigate correlation between backpack carrying, spinal curvatures, and athletic activities on school children's dorsal(DP) and low back pain(LBP). This showed that in the age group of 9-15 years who carried backpacks to their schools experienced back pain in which DP increased with increase in backpack weight and girls experienced much more DBP. It also concluded that at the age of 11 years, girls and boys shoed highest prevalence of dorsal pain, while at the age of 14 years, girls reported significantly more pain than boys ${ }^{20}$. The peak in pain prevalence was immediately before puberty as well as after its onset. Thus, in present study target population was same with similar age group i.e. 10-14 as several studies have shown the occurrence of musculoskeletal pain in the above mentioned age group. Similarly, in the present study target population was girls in the age group of 10-14 where we can find girls who belong to before puberty group along with girls belonging to puberty group as the prevalence of musculoskeletal pain is more in the girls according to the various reviews.

In a study conducted among the school children in the age group of 11.5 to 14.5 years with $15 \%$ of standard backpack weight concluded that $60 \%$ of the children had musculoskeletal pain, shoulder pain being the most prevalent one ${ }^{21}$. In the present study bilateral shoulder pain was most prevalent among girls of 10- 14 years age group because almost all the students carried their backpacks on both shoulder which could be reason for both sides pain.In an observational study where 1800 girls after puberty in the ages of 12 to 17 years were included to measure the thoracic and the kyphosis angle by the use of spinal goniometer concluded that prevalence of kyphosis angle at puberty was $32.44 \% .^{15}$ In this study among 500 girls in the age group of 10-14, 178 of them had a forward head posture and most of them had a rounded back which can be because of the rapid growth and developing secondary sexual characteristics where round back may reflect some degrees of consciousness. ${ }^{15}$ Pain in these areas like shoulder, upper back, lower back and neck is associated with carrying heavy loads ${ }^{22,23}$. Carrying a heavy school bag for long periods of time could result in repetitive stress injuries to the growing body. This follows the shifting of the child's centre of gravity in the direction of the load when 
carrying a backpack ${ }^{22,3}$. To compensate, the child will typically leans in a direction opposite to the force. For example, to compensate for a heavy backpack worn low over the sacrum, the individual typically moves the head and trunk forward. In a cross sectional study among English school children in UK association between ergonomics and other factors were identified in which neck pain was associated with school furniture features, upper back pain was associated with school bag weight along with school furniture features and low back pain was also associated with school furniture features. ${ }^{24}$ In present study neck pain was significant which could be because of heavy backpack and forward head posture which the children attain to maintain balance and posture. Similarly, upper back, thoracic region and low back pain was significant which could be because of heavy backpack.In present study, posture was measured by NYPR scale in which the maximum number of subjects had forward head posture followed by increased thoracic kyphosis, increased lumbar lordosis and forward shoulder posture or rounded back.

\section{Implications:}

With this study we are able to conclude that pain and postural abnormalities are associated with the use of backpacks in children. In this study commonest site of pain is shoulder and frequent postural abnormality noted was a forward head posture. So the problems faced by the school going children can be minimized by reducing the weight of the backpacks along with proper ergonomic alignment of the body.

\section{References}

[1]. Hundekari J, Chilwant K, Vedpathak S, Wadde S. Does alteration in backpack load affects posture of school children?. Group. 2013;2:10-20

[2]. Koley S, Kaur N ,An Association of Backpack Weight and Postural Habits in School Going Children of Amritsar, Punjab, India 2012;2:107111

[3]. Grimmer KA, Williams MT, Gill TK. The associations between adolescent head-on neck posture, backpack weight, and anthropometric features. Spine (Phila Pa 1976) 1999;24:2262-2267.

[4]. Whittfield J, Legg SJ, Hedderley DI. Schoolbag weight and musculoskeletal symptoms in New Zealand secondary schools. Applied Ergonomics. 2005 Mar 31;36(2):193-8.

[5]. Cavallo CM, Hlavaty TM, Tamase MG. A pilot study for the development of a primary prevention program: What is the average weight of a fourth grader's backpack? Work. 20, 2002, 137-158.

[6]. Rai A, Agarawal S. Back problems due to heavy backpacks in school children. IOSR Journal Of Humanities And Social Science (IOSR-JHSS). 2013;10:01-0. Rai A, Agarawal S. Back problems due to heavy backpacks in school children. IOSR Journal Of Humanities And Social Science (IOSR-JHSS). 2013;10:01-0.

[7]. Kendall FP, McCreary EK, Provance PG: Posture and pain,. Baltimore, MD: Williams \& Wilkins. 1993, 4

[8]. Woodhull AM, Maltrund K, Mello BL: Alignment of the human body in standing. European Journal of Applied Physiology. 1985, 54: 109-115.

[9]. Wickens JS, Kipputh OW: Body mechanic analysis of Yale University freshmen. Research Quarterly. 1937, 8: 37-48.

[10]. Raine S, Twomey LT: Head and shoulder posture variations in 160 asymptomatic women and men. Arch. Phys. Med. Rehabil. 1997, 78: 1215-1223.

[11]. Refshauge K, Goodsell M, Lee M: Consistency of cervical and cervicothoracic posture in standing. Australian Journal of Physiotherapy. 1994, 40: 235-240.

[12]. Watson DH, Trott P: Cervical Headache: an investigation of natural head posture and upper cervical flexor performance. Cephalagia. 1993, 13: 272-284. 10.1046/j.1468-2982.1993.1304272.x.

[13]. Datta S, Ramanathan N: Ergonomic comparison of seven modes of carrying loads on the horizontal plane. Ergonomics. 1971, 14: 269-278.

[14]. Legg S: Comparison of different methods of load carriage. Ergonomics. 1985, 28: 197-212.

[15]. Hanfy HM, Awad MA, Allah AH. Prevalence of Thoracic Kyphosis in Girls after Puberty in Cairo Governate. Bulletin of Faculty of Physical Therapy. 2012;17(1).

[16]. von Baeyer CL, Lin V, Seidman LC, Tsao JC, Zeltzer LK. Pain charts (body maps or manikins) in assessment of the location of pediatric pain. Pain. 2011 Jan;1(1):61-8.

[17]. Arnold CM, Beatty B, Harrison EL, Olszynski W. FEATURE ARTICLES-The reliability of five clinical postural alignment measures for women with osteoporosis. Physiotherapy Canada. 2000;52(4):286-94.

[18]. Bijur PE, Silver W, Gallagher EJ. Reliability of the visual analog scale for measurement of acute pain. Academic emergency medicine. 2001 Dec 1;8(12):1153-7.

[19]. Balamurugan J. School bags and musculoskeletal pain among elementary school children in Chennai city. International Journal of Medical Science and Clinical Invention. 2014;1:302-9.

[20]. Korovessis P, Koureas G, Papazisis Z. Correlation between backpack weight and way of carrying, sagittal and frontal spinal curvatures, athletic activity, and dorsal and low back pain in schoolchildren and adolescents. Journal of spinal disorders \& techniques. 2004 Feb 1;17(1):33-40.

[21]. Iyer SR. Musculoskeletal pain in school children. InProceedings of the Human Factors and Ergonomics Society Annual Meeting 2000 Jul 1 (Vol. 44, No. 30, pp. 5-419). SAGE Publications.

[22]. Pascoe DD, Pascoe DE, Wang YT, Shim D-M, Kim CK. Influence of carrying book bags on gait cycle and posture of youths. Ergonomics. 1997;40(6):631-640. doi: 10.1080/001401397187928.

[23]. Haselgrove C, Straker L, 24.Smith A, O’Sullivan P, Perry M, Sloan N. Perceived school bag load, duration of carriage, and method of transport to school are associated with spinal pain in adolescents: an observational study. Aust J Physiother. 2008;54:193-200.

[24]. Murphy S, Buckle P, Stubbs D. A cross-sectional study of self-reported back and neck pain among English schoolchildren and associated physical and psychological risk factors. Applied ergonomics. 2007 Nov 30;38(6):797-804 